\title{
"Suit the Action to the Word, the Word to the Action": An Unconventional Approach to Describing Shakespeare's Hamlet
}

\section{John Patrick Udo}

Ryerson University

\section{Deborah I. Fels}

Ryerson University action": An unconventional approach to describing Shakespeare's Hamlet. Journal of Visual Impairment \& Blindness, 103(3), 178-183.

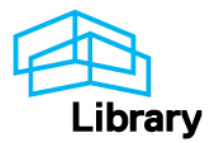


This is a post refereed version of a paper published in the Journal of Vision Impairment \& Blindness. The published version of this paper can be found at http://www.afb.org/afbpress/pubjvib.asp?DocID=jvib0303toc

[2/17/09 master to author]

$<$ boxhd $>$ Practice Report

$<\mathrm{h} 1>$ "Suit the Action to the Word, the Word to the Action": An Unconventional Approach to Describing Shakespeare’s Hamlet

$<$ aa $>$ John Patrick Udo and Deborah I. Fels

$<$ text $>$ Without access to audio description, individuals who are visually impaired (that is, are blind or have low vision) may be at a unique social disadvantage because they are unable to participate fully in a culture that is based on and heavily saturated by the enjoyment of audiovisual entertainments (Packer \& Kirchner, 1997). Audio description was introduced as an adaptive “after-the-fact” strategy to give individuals who are visually impaired better access to entertainment media (Fels, Udo, Ting, Diamond, \& Diamond, 2006). With audio description, visually important elements of the entertainment experience are described during pauses in the dialogue (Packer \& Kirchner, 1997). Conventional audio description practices, as outlined by Snyder (2005, 2007), have been adopted as an access strategy for live theater, television, and film, although little research has informed these practices (Gerber, 2007). Alternative audio description strategies are also being explored and developed, mainly by theater (for example, British Council for the Arts, 2007; Graeae Theatre Company, n.d.) or dance troupes (for 
example, CandoCo Dance Company, 2008; StopGap, 2008) whose mandates are focused on the inclusion of individuals with disabilities in their casts.

We believe that audio description is a creative process, and from working firsthand on live audio description projects, we learned how cognitively demanding live description is on a describer. We recognize that audio describers are generally volunteers and have a genuine interest in making the theater accessible to individuals with visual impairments.

In this article, we present a summary of conventional and alternative audio description practices. We discuss a case account of an alternative audio description strategy that was prepared for a live production of Hamlet using the subjective, emotional style proposed by Fels, Udo, Diamond, and Diamond (2006) and Fels, Udo, Ting et al. (2006); and used by Udo and Fels (in press).

$<\mathrm{h} 2>$ Conventional audio description

$<$ text $>$ Formal audio description is a relatively new media access technology compared with others, such as closed captioning. Audio description has existed for many years, however, as an ad hoc entertainment and access strategy in which friends and family members acted as informal describers, whispering descriptions to their friends and relatives who were visually impaired (Packer \& Kirchner, 1997).

In the 1970s, Gregory Frazier formalized audio description by defining formal procedures and processes for the description of media and cultural events (Snyder, 2005). In the 1990s, WGBH Radio \& Television began offering a Descriptive Video Service as part of its broadcasts (WGBH Educational Foundation, n.d.). Numerous theater groups in the United States and the United Kingdom have also embraced these technologies and techniques for live theater. 
In 1981, Margaret Pfanstiehl and Cody Pfanstiehl were among the pioneers to develop audio description techniques for live theater. Additional guidelines for the creation of audio description for television, film, and live theater exist (Audetel Consortium, 2000; Audio Description International, 2005). However, most of these guidelines tend to rely heavily on anecdotal evidence and the historical use of a specific process, rather than one validated by published research.

Pfanstiehl and Pfanstiehl (quoted in “The Play's the Thing,” 1985, p. 91) cautioned describers "not [to] evaluate or interpret, but rather be like the faithful lens of a camera" and encouraged them to describe visual elements without drawing assumptions for the listener. In doing so, the describer must interpret and translate important visual action or stimuli (costumes, setting, lighting, and so forth) as objectively as possible. Since limited time is available to describe visual stimuli, describers must use precise and highly descriptive language.

There has been limited research on the effectiveness and impact of live audio description on audiences. Although some research on postproduction-produced audio description for documentaries has been conducted (Peli \& Fine, 1996; Schmeidler \& Kirchner, 2001), it is difficult to determine whether this conventional approach is appropriate for theater or whether an alternative approach should be implemented.

$<$ h2> Unconventional audio description

$<$ text $>$ We suggest that conventional audio description does not present users who are blind or have low vision with an experience that is equal or equivalent to that of sighted persons, since it focuses on the description of what is seen—-the set, actors' movements, and lightingrather than on what is meant to be seen-the director's vision. Concentrating exclusively on the visual pieces, rather than on the entertainment experience as a whole, description may impede 
users from suspending their disbelief, constantly reinforcing the lack of access to and dependence on visual stimuli.

Snyder (2005, p. 936) defined audio description as “a literary art form in itself . . . a type of poetry—a haiku," but then suggested that its creation and delivery should be void of subjective interpretation. Whereas an artist's role is primarily defined by and reliant on the subjectivity of self-expression and the audience’s reception (Brocket \& Ball, 2004), Synder (2005) assigned audio describers the impossible task of objective interpretation.

In addition, there is little publicly available evidence that the "camera lens" or objective technique is preferred by audiences of people who are blind or have low vision. Gerber (2007) argued that current audio description practices and processes are flawed because they lack formal input from members of audiences who are visually impaired or theoretical sophistication to support their adoption. Although there has been some research on the creation of and theory behind performances that has included individuals with disabilities (Brewer, 2002; KochharLindgren, 2006; Sandahl, 1999; Strickling, 2002), researchers have only begun a similar process with audio description.

For example, Udo and Fels (in press) discussed the development and implementation of an alternative audio description strategy. Working with a recent graduate of a fashion program, they facilitated the creation of a description strategy that blended color-commentary techniques with conventional audio description for a live fashion show. In their evaluation with members of the audience who were visually impaired or sighted, they found that most participants reported that the describer's commentary and emotional delivery positively affected their enjoyment of the fashion show. 
Fels, Udo, Diamond et al. (2006) and Fels, Udo, Ting et al. (2006) used a similar creation process for an alternative audio description strategy for the adult-oriented cartoon show Odd Job Jack, shown on the Canadian Comedy Network cable channel. They found that users who were blind or had low vision reported that the alternative approach was more entertaining, although less informative.

These experiences lead us to suggest that audio description could be considered one of the many creative components of an entertainment experience. The creation and execution of audio description would thus fall to the director and creative team, since they are best able to develop, from the beginning, a strategy for audio description that is reflective of and true to the purpose and goal of the entertainment. Describers would be considered part of the creative team, even if it was a temporary association related to a specific venue or date. Interested individuals could also consider the possibility of consulting with playwrights to create complimentary audio description for a play that has already been published or on a project that is currently in development.

$<$ h2 $>$ An alternative audio description strategy

$<$ text>Andrea Wasserman, director of Hart House Theatre’s production of Hamlet, worked with Paul Leishman, the audio describer, to create, develop, and perform an alternative audio description strategy that would remain true to the director's initial vision, entertain the audience, use stylistically similar dialogue, provide an additional avenue for audience members (sighted and visually impaired) to access meaning, and be seamlessly incorporated into the entertainment experience. The conventional audio description process, advocated by Pfanstiehl \& Pfanstiehl (“The Play’s the Thing,” 1985) and Synder (2005), takes some of these goals into account, although the execution of these goals is not controlled by the director from the 
beginning of the production. In this section, we present one example of how a director's involvement in and control of an alternative audio description strategy for her production made the attainment of these goals different from conventional practices.

In her director's notes, Wasserman (2006) described her understanding of Hamlet, as a play and a protagonist:

$<\mathrm{ext}>$

Just when we think Hamlet might jump to his revenge, some new torturous betrayal is discovered—so much so that the man has little time for action! He is barraged with fear, loss, and self-hatred all while trying to mourn the death of his father. With all of this on his plate, can we really blame him for taking some time to think things through? If only everyone who feels prompted to revenge would take the same time! With design elements that salute the renaissance, this production explores Hamlet as a journey with no clear paths: where truth and lies intermingle and become meaningless and where peace is found only by wiping the slate clean and beginning afresh.

$<$ text $>$ Wasserman made use of several theatrical conventions to communicate her complex vision. For example, the stationary set that was created for the production was multilevel, enabling actors to conceal themselves behind portions of it or make unexpected entrances or exits. Wasserman wanted to use the setting to physically represent Hamlet's mental struggle (personal communication, May 14, 2008).

To make her production accessible and entertaining for an audience of people who are visually impaired, Wasserman also considered how nontraditional theatrical mediums could be used to communicate visual meaning. Working with the research team, Wasserman and Paul Leishman (the describer) learned about conventional audio description. Leishman thought that 
performing the descriptions in traditional Shakespearian form (iambic pentameter) and in a similar style would match the dialogue in the play. The director thought this was an interesting idea that would fit well with the play.

The description script, which was created by Leishman, highlighted Hamlet's inability to find clear answers to his questions or solutions to his problems. For example, Leishman (2006) used a maze metaphor to express Hamlet’s confusion:

$<\mathrm{ext}>$

A home is now transformed into a maze

As Hamlet passes through the castle halls;

Upstairs to landings leading to more stairs

Through secret chambers into hidden rooms.

$<$ text $>$ It should be noted that this description does not give users of audio description an exact layout of the stage, but communicates the idea behind it. Giving users a precise and detailed account of the set may have given them equal access to the information that Wasserman sought to provide viewers, but it would have lessened their ability to access the metaphorical meaning that the set was constructed to support. Brockett and Ball (2004, p. 22) noted that "the spectator may need to imagine much that is merely suggested by a few set pieces, project images, lighting, or dialogue, and the same basic setting may be used to represent quite different locales.” Therefore, directors depend on the willingness of theatergoers to suspend their disbelief, so it would seem reasonable that theatergoers who are blind or have low vision have the opportunity to have the same experience.

In Act 1, Scene 2, Leishman (2006) offered a description of a great ball, concerned more with capturing the director's vision of the set, rather than the set itself: 
$<\operatorname{ext}>$

A great Ball is set within the Castle

in the grandest room as wide, high and clear

all paths, stairs, landings in the Castle large,

lead to the Hall of the celebration.

The ball—enflamed in fire from torches lit-

is full of Princes and ambassadors.

The Lords and Ladies dance. And dance. And drink, with courtly manners, ply their country games.

$<$ text $>$ A conventional audio description would have taken a more objective, less interpretative approach, relaying factual information about the set, costumes, and characters’ actions. This approach might have resulted in the creation of the following audio description:

$<$ ext $>$

Red and yellow hues fill the stage.

Dressed in lavish costumes, Lords and Ladies dance and drink.

$<$ text $>$ Compared with the alternative description, the conventional approach to audio description is remarkably shorter and more concerned with providing visual information than catering to the feel of the scene. Whereas conventional audio description often uses color to communicate a visual image ("red and yellow hues fill the stage”), the director’s alternative description focused on the use of sensory-based images that did not depend on sight ("the ball—enflamed in fire from torches lit”). Inspired by the scene presented, the describer worked with the director to translate a visual image aurally while serving to embellish it. 
Hamlet's deathbed request inspired the describer to suggest Horatio as a first-person audio describer, similar to the technique used by Fels, Udo, Diamond et al. (2006) and Fels, Udo, Ting et al. (2006). Mortally wounded in Act 5, Scene 2, Hamlet charges Horatio with the responsibility of retelling his story:

$<$ ext $>$

If thou didst ever hold me in thy heart

Absent thee from felicity awhile,

And in this harsh world draw thy breath in pain,

To tell my story. (Shakespeare, n.d.)

$<$ text>Foreshadowing Horatio’s role at the end of the play, Leishman (2006) introduced and overtly identified Horatio's role as a storyteller. In the dark of the theater, Leishman aurally introduced himself as Horatio to the users of audio description:

$<$ ext $>$

You, who ask, who shall speak this old tale true,

T' is I, one Horatio, a friend.

$<$ text $>$ Through this introduction, the audio description script challenges preconceived notions of audio description by having Horatio answer two questions that are ordinarily assumed: "Who am I?” and “What am I doing?” Scripted by the describer, Horatio’s introduction answers both questions, since he is a storyteller who is recounting events. Whereas conventional audio description assumes that users already know the answer to these questions (namely, "I'm a describer" and "I'm aurally describing what is visually occurring on stage"), the unconventional audio description strategy developed for Hamlet by the director did not assume or imply its role as an access strategy. 
Even though Horatio's introduction answers these two questions, it also leaves the listener dangling because Horatio he does not explain his motivation for retelling his story. Only in Act 5, within the play itself, does the director allow for this motivation to be revealed using Shakespeare's dialogue. Evident here is the director's desire to enmesh the experience offered by the play and the audio description further into a complete narrative. The audio description creates an alternate vehicle through which the audience comes to know and appreciate the play because it foreshadows the importance of Horatio as a friend to Hamlet and as a character to Shakespeare. The director chose to ensure that the audio description listeners realized, only at the end of the play, that Horatio did indeed keep his word, for he is retelling the story to them.

We assert that it is important to respect the intentions and decisions made by the creative team to create a production that is true to the director's initial vision. We also suggest that audio description should be overseen by a director, since it is his or her creative vision that propels a production. 
$<$ h2 $>$ References

Audetel Consortium. (2000). ITC guidance on standards for audio description. Retrieved from http://www.ofcom.org.uk/static/archive/itc/itc_publications/codes_guidance/ audio_description/Index.asp.html

Audio Description International. (2005). Guidelines for audio description. Retrieved http://www.adinternational.org/ADIguidelines.html

Brewer, D. (2002) West side silence: Producing West Side Story with deaf and hearing actors. Theatre Topics 12(1),17-34.

British Council for the Arts. (2007). Arts in performance profile: Extant. Retrieved from http://www.britishcouncil.org/arts-performanceinprofile2007-extant.htm

Brocket, O. S., \& Ball, R. J. (2004). The essential theatre (8th ed.). Belmont, CA: Wadsworth. CandoCo Dance Company. (2008). Home. Retrieved from http://www.candoco.co.uk/index.php?tm=12

Fels, D. I., Udo, J. P., Diamond, J. E., \& Diamond, J. I. (2006). A comparison of alternative narrative approaches to video description for animated comedy. Journal of Visual Impairment \& Blindness, 100, 295-305.

Fels, D. I., Udo, J. P., Ting, P., Diamond, J., \& Diamond, J. (2006). Odd Job Jack described: A universal design approach to described video. Journal of Universal Access in the Information Society 5(1), 73-81.

Gerber, E. (2007). Seeing isn’t believing: Blindness, race and cultural literacy. Sense and Society 2(1), 27-40.

Graeae Theatre Company. (n.d.). About us. Retrieved from http://www.graeae.org/production/flowergirls/writing 
Kochhar-Lindgren, K. (2006). Hearing difference across theatres: Experimental, disability and deaf performance. Theatre Journal, 58, 417-436.

Leishman, P. (2006). Hamlet: Audio description script. Toronto: Hart House Theatre.

Packer, J. \& Kirchner, C. (1997). Who's watching? A profile of the blind and visually impaired audience for television and video. New York: American Foundation for the Blind. Retrieved from http/www.afb.org/Section.asp?SectionID=3\&TopicID=135\&DocumentID=1232

Peli, E., \& Fine, E. M. (1996). Evaluating visual information provided by audio description. Journal of Visual Impairment \& Blindness, 90, 378-385.

The play’s the thing. (1985). British Journal of Visual Impairment, 3, 91-92.

Sandahl, C. (1999). Ahhh freak out! Metaphors of disability and femaleness in performance. Theatre Topics, 9(1), 11-30.

Schmeidler, E., \& Kirchner, C. (2001). Adding audio description: Does it make a difference? Journal of Visual Impairment \& Blindness, 95, 198-212.

Shakespeare, W. (2005). Hamlet. Retrieved from http:// Shakespeare,mit.edu/hamlet/full.html Snyder, J. (2005). Audio description: The visual made verbal. International Congress Series, 1282, 935-939.

Snyder, J. (2007). Audio description: The visual made verbal. Retrieved from http://www.audiodescribe.com/about/articles/ad_international_journal_07.pdf

StopGap Dance Company. (2008). About us. Retrieved from http://www.stopgap.uk.com

Strickling, C. A. (2002). Actual lives: Cripples in the house. Theatre Topics, 12, 143-162.

Udo, J. P., \& Fels, D. I. (in press). Re-fashioning fashion: An exploratory study of a live audio described fashion show. Universal Access in the Information Society. 
Wasserman, A. (2006). Hamlet: Director's notes. Toronto: Hart House Theatre.

WGBH Educational Foundation. (n.d.). DVS FAQ. Retrieved from http://main.wgbh.org/wgbh/pages/mag/services/description/dvs-faq.html

[QUERY 12: In the authors' blurb, please provide the job title for Udo. Also, please verify all the other information in the blurb, some of which was taken from the university's web site as well as your $2006 \mathrm{JVIB}$ article.]

<aubio>John Patrick Udo, M.A., SRC Associate, Center for Learning Technology, Ryerson University, 350 Victoria Street, Toronto, Ontario M5B 2K3 Canada; e-mail: <judo@ryerson.ca>.Deborah I. Fels, Ph.D., director, Center for Learning Technology, Ryerson University; e-mail: <dfels@ryerson.ca>. 